\title{
STUDIES ON THROMBOLYTIC AND ANTI-HELMINTIC ACTIVITY OF Cocccinea grandis
}

\section{B. Deepti*, P. Srinivasa Babu, Anusha and Balakishore}

\begin{abstract}
Vignan Pharmacy College, Vadlamudi, Guntur, Andhra Pradesh 522213, India
\end{abstract}

Submitted: $11-07-2013$

Revised: 23-11-2013

Accepted: $16-12-2013$

*Corresponding author B.Deepti

Email :

deepubandarupalli@ gmail.com

\begin{abstract}
Traditional system of medicine consists of large number of plants with various medicinal and pharmacological values and hence represents a priceless tank of new bio active molecules. Coccinea grandis belongs to the family Cucurbitaceae, is a rapidly growing, perennial climber or trailing vine. Traditionally different parts of this plant namely roots, leaves, and fruits are used in folklore medicine for several purposes like jaundice, diabetes, wound healing, ulcers, stomach ache, skin disease, fever, asthma, cough. Development of anthelmintic resistance and high cost of conventional anthelmintic drugs led to the evaluation of medicinal plants as an alternative source of anthelmintics. As no scientific data was available on this plant hence, the present study was carried out for the investigation of antihelmintic activity and thrombolytic activity of bark of Coccinea grandis. Antihelmintic activity was done on pheritima posthuma. The results obtained were compared with standard albendazole and control groups respectively, the parameters evaluated are time of paralysis and time of death. On the other hand thrombolytic activity was done by using aqueous extract of Coccinea grandis bark. Thrombi or emboli can lodge in a blood vessel and block the flow of blood in that location depriving tissues of normal blood flow and oxygen. This can result in damage, destruction (infarction), or even death of the tissues (necrosis) in that area. Streptokinase is an antigenic thrombolytic agent used for the treatment of acute myocardial infarction, served as standard. This study was conducted on human blood sample and compared with standard and control groups respectively. The parameters studied are percentage of clot lysis. From the present study we found that various extracts of this plants showed significant thrombolytic and antihelmintic properties.
\end{abstract}

Key words: thrombolysis, helminthes, coccinea, albendazole, streptokinase.

\section{INTRODUCTION}

Medicinal plants are various plants used in herbalism and thought by some to have medicinal properties. Few plants or their phytochemical constituents have been proven to have medicinal effects by rigorous science or have been approved by regulatory agencies such as the United States Food and Drug Administration or European Food Safety Authority (Tapsell et al., 2006).

They usually contain many biologically active ingredients and are used basically for treating mild or chronic ailments. According to World Health Organization (WHO), about $80 \%$ of the world population entrust chiefly on the plant based traditional medicine especially for their primary healthcare needs John \& francis, 2011). Herbal medicines are in great demand in the developed as well as developing countries for primary healthcare because of their wide biological and medicinal activities, higher safety margins and lesser costs. Hence, this study reveals the scientific investigation of Coccinea grandis.

Coccinea grandis native range extends from Africa to Asia. This is commonly called as ivy gourd. Coccinia grandis is a perennial growing to $3 \mathrm{~m}$ (9ft 10in). In traditional medicine, fruits have been used to treat leprosy, fever, asthma, bronchitis and jaundice. The juice of the roots and leaves is considered to be a useful treatment for diabetes. The juice of the stem is dripped into the eyes to treat cataracts. The leaves are used as a poultice in treating skin eruptions. The plant is also used as laxative and is used internally in the treatment of gonorrhoea (Linney, 1986).

Thrombolysis is a process of dissolving and breaking clots. It is nothing but dissolution and destruction of clots. It involves the interaction of clot components with surrounding plasma. Because of the slight availability of the thrombolytic drugs, trials are in progress to spring up recombinant variants of this drugs 
(Lijnen etal., 1991). The present trial was done to inspect the thrombolytic activity of Coccinia grandis.

Helminth infections are among the abounding global infections in humans, distressing a huge population of the world. Helminthiasis is among the most important animal diseases inflicting heavy production losses. Helminthes control in domestic animals is extensively based on the use of antihelmintic drugs. The current efficacy of the available drugs had been reduced because of the resistant nematode strains (Mali \& Wadekar, 2008). The high costs of the drugs have enliven an interest in medicinal plants as an alternatives source of antihelminthic drugs. Based on this an attempt has been made to evaluate the antihelminthic potential of Coccinia grandis.

\section{METHODOLOGY}

\section{Collection of plant material}

Bark of Coccinea grandis were collected and dried under shadow. The dried bark is finely powdered and stored in polythene bags at room temperature $\left(30 \pm 2^{\circ} \mathrm{C}\right)$ until use.

\section{Extraction of plant materials}

$100 \mathrm{grms}$ of coarse powder of air dried bark of Coccinea grandis were packed in mucilin cloth and subjected to soxhlet extraction for continuous hot extraction with distilled water, acetone and chloroform for 8hrs separately. Then each extracts were filtered and filtrate was evaporated to dryness.

\section{Method for estimation of thrombolytic activity}

Whole blood $(5 \mathrm{~mL})$ was drawn from healthy human volunteers $(n=10) .500 \mathrm{ml}$ of blood was transferred to each of the ten previously weighed Eppendorf tubes and incubated at $37^{\circ} \mathrm{C}$ for $45 \mathrm{~min}$. After clot formation, serum was completely removed and record the weight. Each Eppendorf tube containing clot was properly labelled and plant extracts were added to the tubes. All the tubes were then incubated at $37^{\circ} \mathrm{C}$ for $90 \mathrm{~min}$ and observed for clot lysis. $\%$ of clot lysis $=$ (wt of released clot / clot wt) $\times 100$ (Prasad etal., 2006).

\section{Method for estimation of anthelminthic activity}

The anthelminthic assay was performed on adult Indian earth worm Pheretima posthuma as it has anatomical and physiological resemblance with the intestinal round worm parasites of human beings (Ghosh etal.,2005). ..Six worms of nearly equal size were introduced in to each of the petri plates. Observations were made for the time taken to paralysis and death of individual worm. The mean time for paralysis was noted when no movement of any sort could be observed, except when the worm was shaken vigorously; the time death of worm (min) was recorded after ascertaining that worms neither moved when shaken nor when given external stimuli. The test results were compared with Reference compound Albendazole $(15 \mathrm{mg} / \mathrm{ml})$ treated samples. Statistical significance of the data was assessed by analysis of variance ANOVA.

\section{RESULTS AND DISCUSSION}

A number of studies have been conducted by various researchers to find out the herbs and natural food sources and their supplements having antithrombotic (anticoagulant and antiplatelet) effect and there is evidence that consuming such food leads to prevention of coronary events and stroke. Addition of 250 and $500 \mu \mathrm{g}$ of aqueous extract of Coccinea grandis has showed significant thrombolytic activity (69 \& 72\%) when compared to control (3\%) and standard (68\%). This was statistically represented in graph 1. This thrombolytic activity is might be due to the activation of plasminogen activator. From the observations made, higher concentration of extract produced paralytic effect much earlier and the time to death was shorter for all worms. Acetone extract showed anthelmintic activity in dose-dependent manner giving shortest time of paralysis (P) and death (D) with 12.5 and $25 \mathrm{mg} / \mathrm{ml}$ concentrations (14 \& $9 \mathrm{~min})$, (59 \& 50min). This is represented in graph 2. Phytochemical investigation revealed the presence of steroids, resins, tannins, flavonoids and phenols in acetone extract. Where as chloroform extract showed the presence of steroids, resins and tannins. Tannins, the polyphenolic compounds, are shown to interfere with energy generation in helminth parasites by uncoupling oxidative phosphorylation and cause death (Prasad etal., 2007). Hence, further investigation and proper isolation of the active principles might help in the findings of new lead compounds, which will be effective against various parasitic infections. 
Clot lysis of Coccinea grandis

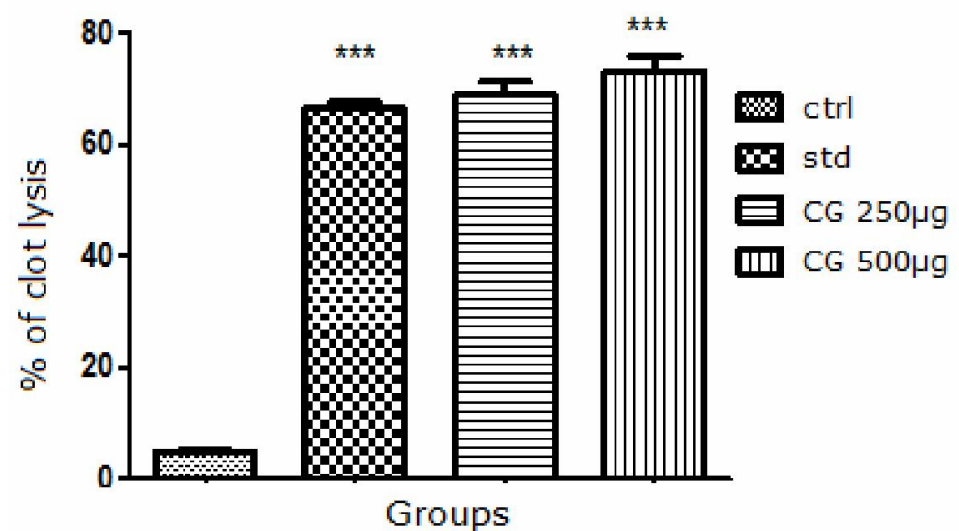

Figure 1. Evaluation of thrombolytic activity of Coccinea grandis (Values are expressed as mean \pm SEM $(\mathrm{n}=10),{ }^{* * *}(\mathrm{p}<0.001)$ vs control group )

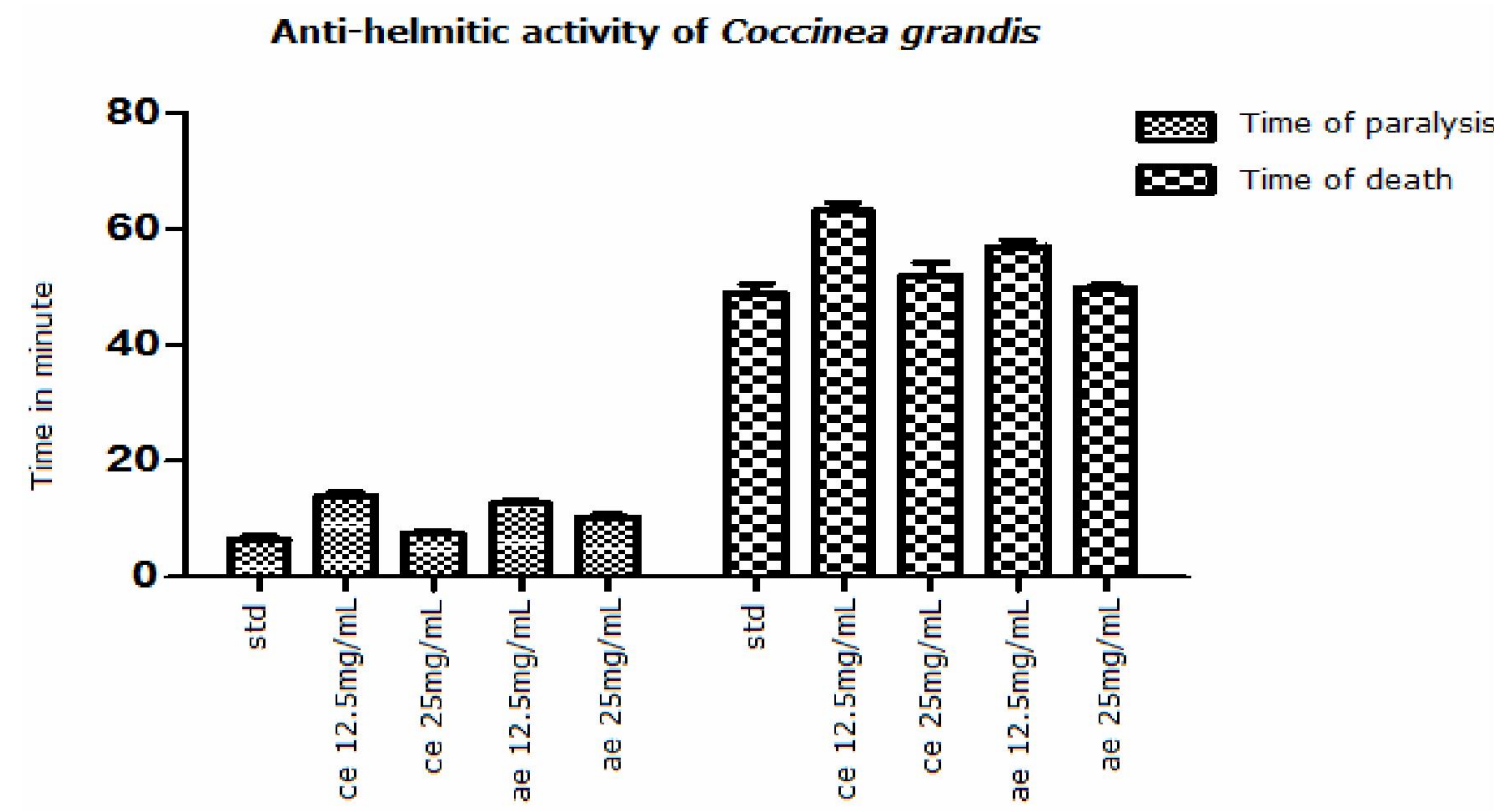

Figure 2. Evaluation of Antihelmintic activity Coccinea grandis

Values are expressed as mean \pm SEM $(n=6)$

\section{CONCLUSION}

The results of the present study indicated that aqueous extract has shown significant thrombolysis, where as acetone and chloroform extracts exhibits interesting antihelmintic activity which may be due to presence of Tannins, flavonoids, steroids and resins. The plant should be further screened for the development of new pharmaceuticals that address hither to unmet needs.

\section{ACKNOWLEDGEMENTS}

The authors are thankful to management of Vignan Pharmacy College, Vadlamudi for providing necessary facilities to carry out present research work. 


\section{REFERENCES}

Dash GK,, Suresh P., Kar DM., Ganpaty, S., Panda SB., 2002, Evaluation of Evolvulus alsinoides Linn. For anthelmintic andantimicrobial activities, $J$ Nat Rem., 2: 182-185.

Ghosh T., Maity A., Bose and Dash GK. 2005, Anthelmintic activity of Bacopa monierri, Indian .J Nat Product :21;16-19.

John K., Francis., 2011, "Senna occidentalis (L.) Link", International Institute of Tropical Forestry., 10-17.

Kamal-Hossain Md., Musfizur-Hassan Md., Nazma-Parvin Md., Mahmudu-Hasan Md., Siddiqu-Islam Md., and AhsanulHaque Md., 2012, Antimicrobial, cytotoxic and thrombolytic activity of Cassia senna leaves (family: Fabaceae), J.App. Pharm. Scie.., 06;186-190.

Lijnen HR., Vanhoef B., DeCock F., Okada K., Ueshima S., Matsuo O., 1991. On the mechanism of fibrin-specific plasminogen activation by staphylokinase, J Biol Chem, 266:11826-11832
Linney G., 1986, "Coccinia grandis (L.) Voight: A new cucurbitaceous weed in Hawai'i", Hawaii Botanical Society Newsletter., 25 (1): 3-5.

Mali, R.G., Wadekar, R.R., 2008, In Vitro anthelmintic activity of Baliospermum montanum Muell. Arg roots, Indian J Pharm Sci., 131-133.

Prasad, S., Kashyap, R.S., Deopujari, J.Y., Purohit, H.J., Taori G.M., and Daginawala, H.F., 2006, Development of an in vitro model to study clot lysis activity of thrombolytic drugs, Thromb. J., 4(14): 1-4.

Prasad, S., Kashyap, R.S., Deopujari, J.Y., Purohit, H.J., Taori G.M., and Daginawala, H.F., 2007, Effect of Fagonia Arabica (Dhamasa) on in vitro thrombolysis, BMC Comp. Alter. Med., 7(36): 1-6.

Tapsell, L.C., Hemphill, I., Cobiac, L., et al., 2006, "Health benefits of herbs and spices: the past, the present, the future", Med. J. Aust., 185 (4 Suppl): S4-24 